\title{
MODOS DE CONHECER E INTERVIR: A CONSTITUIÇÃO DO CORPO NO CUIDADO DE ENFERMAGEM NO HOSPITAL ${ }^{1}$ MANNERS OF KNOWING AND INTERVENING: THE CONSTITUTION OF THE BODY IN HOSPITAL NURSING CARE LOS MODOS DE CONOCER Y INTERVENIR: LA CONSTITUCIÓN DEL CUERPO EN EL CUIDADO DE ENFERMERÍA EN EL HOSPITAL
}

\author{
Rosemeiry Capriata de Souza Aževedo², Flávia Regina Souza Ramos³
}

${ }^{1}$ Trabalho apresentado no $3^{\circ}$ Seminário Internacional de Filosofia e Saúde, Florianópolis, outubro de 2006.

${ }^{2}$ Doutora em Enfermagem. Docente do Programa de Pós-Graduação em Enfermagem da Universidade Federal de Mato Grosso (UFMT). Membro do Grupo de Pesquisa Argos na UFMT. Mato Grosso, Brasil.

${ }^{3}$ Doutora em Enfermagem. Docente do Programa de Pós-Graduação em Enfermagem da Universidade Federal de Santa Catarina (UFSC). Membro do Grupo de Pesquisa Práxis na UFSC. Santa Catarina, Brasil.

PALAVRAS - C HAVE: Enfermagem. Cuidados de enfermagem. Assistência hospitalar.

KEYWORDS: Nursing. Nursing care. Hospital care.

PALABRAS CLAVE: Enfermería. Atención de enfermería. Atención hospitalaria.
RESUMO: Trabalho analisa a maneira como o corpo é constituído em objeto de conhecimento e intervenção, pela enfermeira no cuidado hospitalar. Dados foram coletados por meio de observações de campo, análise de prontuários e livro de passagem de plantão das enfermeiras, no período de 2000 a 2003. A análise revelou que o ritual de internação é traçado pelas lógicas da instituição, dos profissionais médicos e pelo saber construído sobre o sujeito. O exame dá visibilidade ao poder médico, esquadrinha o corpo e objetiva o doente sujeitando-o às verdades de um campo de saber. O cuidado de enfermagem se expressa em exercícios de poder, rituais, dispositivos, simbolizações e jogos de interesses que circulam, tramam e o sustentam no hospital. Por conseguinte o corpo produzido é fragmentado, com múltiplos domínios, disciplinado, vigiado; corpo tomado pela doença. O hospital se revelou como um corpo "construído", ao mesmo tempo em que "constrói" corpos.

ABSTRACT: This work analyzes the way the body is built as an object of knowledge and intervention by the nurse who provides hospital care. Data was collected through field observations, handbook analysis, and nursing charts and records from 2000 to 2003. The analysis reveled that internment is traced from institutional logic, from medical professionals, and from knowledge built upon the subject. The exam gives visibility to medical power, investigates the body and objectifies the sick, subjecting him to the truths of a field of knowledge. Nursing care expresses itself in exercises of power, rituals, devices, symbolizations, and interest games that circle, conspire and support themselves in the hospital. Therefore the body produced is broken up with multiple domains, disciplined, watched; body taken by the illness. The hospital has revealed itself as a "constructed" body at the same time that it "constructs" bodies.

RESUMEN: El presente trabajo analiza los modos en que el cuerpo se constituye en un objeto de conocimiento e intervención de la enfermera en el cuidado en el hospital. Los datos fueron recolectados en el período de 2000 a 2003, por medio de observaciones de campo, análisis de manuales y el libro de registro del turno de las enfermeras. El análisis reveló que el ritual de internación es hecho desde la lógica de la institución, de los profesionales médicos y del saber construido en relación al sujeto. El examen da visibilidad al poder médico, examina el cuerpo y objetiva el paciente sujetándolo a las verdades de un campo de conocimiento. El cuidado de enfermería se expresa en los ejercicios de poder, rituales, dispositivos, simbolizaciones y juegos de intereses que circulan, traman y lo sostienen en el hospital. Por lo tanto, el cuerpo producido es fragmentado, con dominios múltiples, disciplinado, vigilado; tomado por la enfermedad. El hospital se reveló como un cuerpo "construido", al mismo tiempo que "construye" los cuerpos.
Endereço: Rosemeiry Capriata de Souza Azevedo R. C, $\mathrm{n}^{\circ}$ 33, Cond. Matisse Residences, Bl. B, Ap. 501 78.048-298 - Miguel Sutil, Cuiabá, MT, Brasil. E-mail capriata@terra.com.br
Artigo original: Pesquisa

Recebido em: 24/10/2006 Aprovação final: 23/04/2007 


\section{INTRODUÇÃO}

Este trabalho é um recorte da Tese de Doutorado cujo título é o mesmo do artigo, apresentada ao Programa de Pós-Graduação de Enfermagem (PEN) da Universidade Federal de Santa Catarina (UFSC) em 2005 e busca apresentar a "constituição de corpo" a partir do ritual de internação, exame físico e cuidado desenvolvido no ambiente hospitalar.

A construção do saber sobre o corpo pelos profissionais de enfermagem se dá sobre um corpo específico, o corpo doente, apoiado no modelo biomédico de atendimento à saúde, construído no interior da prática médica, detentora da legitimidade do domínio dos saberes e intervenções dirigidas à saúde e à doença. Por isso, a forma de ver, pensar, lidar e cuidar dos doentes, com todos os meios conhecimentos, técnicas e materiais - se concretiza na maneira/modos de organizar, produzir e reproduzir a vida social e biológica.

Pensar e teorizar sobre o corpo como objeto de trabalho da enfermagem a partir de seus significados traz à tona a necessidade de identificar como se dá à construção do saber sobre o corpo e como esse saber se transformou num exercício de poder para a enfermeira/profissionais de enfermagem no cotidiano de sua prática profissional.

A busca por essa compreensão passa por novos questionamentos: como o corpo está sendo construído dentro da estrutura hospitalar? Que relações foram/estão sendo estabelecidas com esse corpo? Que fatores têm sido determinantes nesta relação? Como a enfermagem foi se apropriando do corpo do cliente? Como o conhecimento da enfermagem se constituiu como uma verdade, outorgando poder para intervir sobre o corpo dos clientes? Que concepções de corpo têm apoiado os cuidados de enfermagem?

\section{PERCURSO METODOLÓGICO}

O estudo se apóia nas idéias de Michel Foucault, por pensar de outro modo processos que são, muitas vezes, naturalizados. Suas obras/pensamentos nos incitam a estranhar o que parece natural, a buscar na raridade do cotidiano, aparentemente banal, elementos que permitam construir um inventário que, com o esforço criativo do pesquisador, se torna possível captar um recorte, por vezes, inusitado da realidade histórica.

A abordagem genealógica serviu de inspiração para o desenvolvimento do trabalho e orientou a postura da pesquisadora frente aos dados a serem analisados. O método não forneceu uma sequiência rígida de etapas e procedimentos a serem seguidos, mas "iluminou" o caminho.

O método genealógico se opõe ao histórico tradicional; seu objetivo é assinalar a singularidade dos acontecimentos, fora de toda finalidade monótona. A história genealógica trabalha com a descontinuidade, desfaz os pontos fixos, quebra as identidades e introduz o corpo na História. Ela é meticulosa; exige, portanto, a minúcia do saber, evitando a todo custo o que está acima da história, suas significações ideais; exige paciência. ${ }^{1}$

Ao invés de tomar como verdade absoluta que a enfermagem exerce um poder totalitário e dominador sobre o corpo do cliente no momento do cuidado, adotou-se a postura de um "caçador de tesouros" que sai em busca de pistas, imagens, coisas ditas (textos) e de visibilidades (técnicas e procedimentos gerados institucionalmente) para problematizar, promover estratégias de estranhamento, colocando sob suspeita os significados produzidos no contexto hospitalar e suas implicações para o cuidado.

A equipe de enfermagem (enfermeiras, auxiliares e técnicas de enfermagem) foram os sujeitos participantes do estudo, uma vez que o cuidado prestado ao cliente não acontece de forma isolada, mas num conjunto de relações que os sujeitos estabelecem entre si.

O estudo foi realizado na clínica médica de um hospital universitário, localizado na região centro-oeste do país. A clínica foi escolhida em virtude da baixa rotatividade de seus clientes (média de permanência de 20 a 25 dias) permitindo, assim, maior aproximação com a realidade e dinâmica desenvolvida pela equipe de enfermagem no desenvolvimento do cuidado. Também pelo vínculo profissional e experiência com o serviço, pois o hospital serve de campo de estágio para a Faculdade de Enfermagem e desenvolvimento de atividades docente-assistenciais.

Os dados foram coletados após aprovação do Comitê de Ética em Pesquisa por meio de observação, entrevistas/diálogos informais, análise de documentos como os prontuários dos clientes ( 80 prontuários), livro de registro de passagem de plantão das enfermeiras (6 livros) no período de 2000 a 2003 e o Manual de Normas e Procedimentos de Enfermagem das unidades de internação clínica médico-cirúrgica. $\mathrm{O}$ número 
de aprovação no Comitê de Ética em Pesquisa do trabalho é 083/HUJM/2002. O referido projeto foi aprovado em reunião do Comitê de Ética em 04 de dezembro de 2002.

A observação foi realizada no período de novembro de 2002 a fevereiro de 2003. Todas as observações realizadas foram registradas em Diário de Campo, imediatamente após as situações observadas, posteriormente digitadas e agrupadas. As entrevistas foram realizadas após assinatura do Termo de Consentimento Livre e Esclarecido e garantia de anonimato dos entrevistados.

Após leitura exaustiva das observações contidas no diário de campo foi montado o quadro denominado "notas reconstitutivas"*, a partir do seguinte questionamento: de que modo o corpo está sendo construído aqui? Ao tentar responder a essa questão comecei a me aproximar do referencial teórico e a desvelar o objeto de estudo.
Os prontuários forneceram dados acerca do cliente - identificação pessoal, procedência, condições socioeconômicas, atividade profissional, manifestações clínicas, diagnóstico, terapêutica instituída, cuidados executados, dentre outros. No livro de passagem plantão se obteve informações acerca da hierarquia que se estabelece na estrutura hospitalar (solicitações/encaminhamentos administrativos), relações médico/enfermeira, médico/cliente e relatos que revelavam os bastidores e redes de poderes instituídos no hospital, a partir de cenas e registros descritos por enfermeiras da clínica.

Esses registros passaram pelo "filtro" das enfermeiras, susceptíveis às dificuldades das condições de trabalho, relações interpessoais, emoções vividas por cada um no momento do registro.

Os dados foram analisados com base no referencial foucaultiano, especialmente inspirados na orientação genealógica, obedecendo ao percurso sintetizado no esquema abaixo:

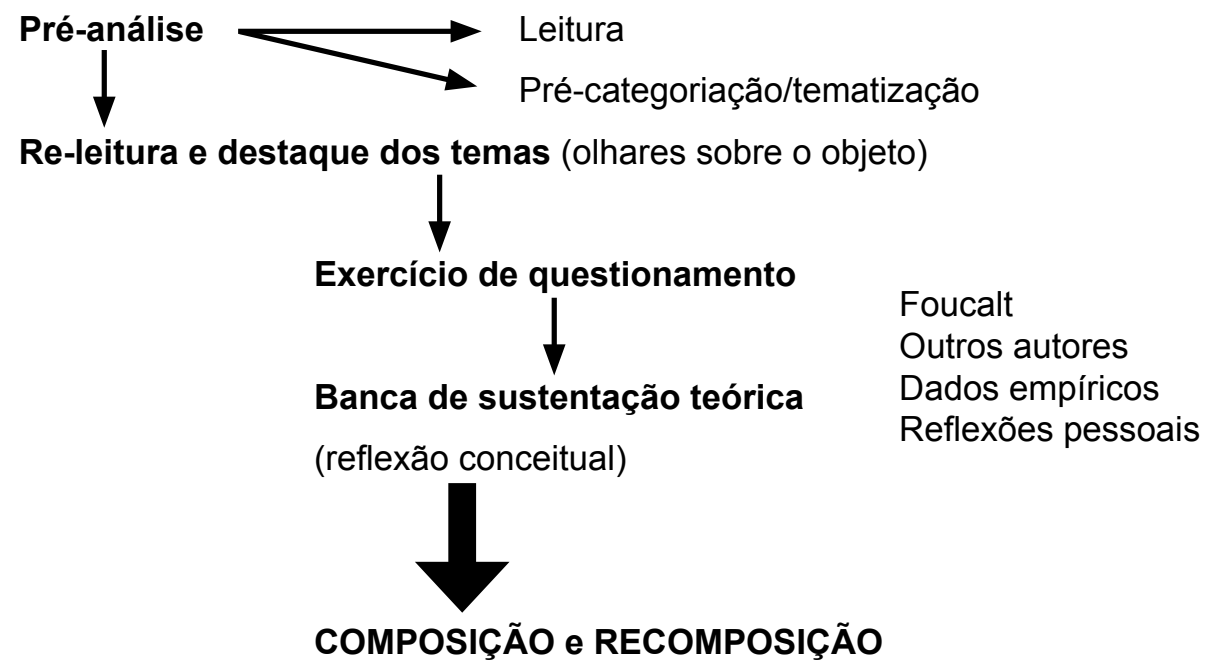

Tema destrinchado, substanciado (corpo teórico)

Diálogo final com os dados e apresentação dos

achados em sua significação "reconstituída"

Vale ressaltar, que esta é uma divisão didática que tem por objetivo apresentar ao leitor o movimento realizado pelo pesquisador no processo de organização e reorganizção dos dados colhidos.

A pré-análise foi constituída de leitura exaustiva do material empírico na tentativa de identificar como se construiu os saberes sobre o corpo e sua relação com o cuidado desenvolvido pela enfermeira. Em seguida passei a pré-categorizar/tematizar os achados, com base em categorias teóricas pré-definidas, tais como: a relação saber-poder, constituição do discurso de saberes, corpo e cuidado, e categorias empíricas que foram surgindo à medida que os dados foram sendo destrinchados, apontando novas facetas e questões sobre o objeto.

\footnotetext{
* Notas reconstitutivas - são notas em que eu coloco a interpretação pessoal, de forma livre e/ ou associada à literatura, no sentido de me aproximar da compreensão de como o corpo está sendo construído nos diferentes momentos do cuidado.
} 
A partir do questionamento "de que modo o corpo está sendo construído aqui?” busquei dar visibilidade à dinâmica do trabalho e à produção de corpo no cuidado num exercício de decomposição do tema para em seguida buscar a sustentação teórica (reflexão conceitual) estabelecendo assim, um diálogo entre o referencial teórico de Michel Foucault, outros autores, dados empíricos e reflexões pessoais que foram registradas nas notas reconstitutivas para, em seguida, desenvolver o processo de composição e recomposição do tema destrinchado, realizando um diálogo final com os dados, apresentando os achados em sua significação "reconstituída", visto que a significação não é literal, mas a significação atribuída pelo pesquisador.

Sempre haverá vários significados ao objeto e à realidade observada. Eu reconstituí os "quadros", "retratos" desta realidade com o "meu olhar", que traz consigo vivências influenciadas por um referencial que é próprio.

\section{A “RE-CONSTRUÇÃO” DO CORPO NO HOSPITAL}

\section{O corpo internado: a entrada na instituição}

Antes da internação propriamente dita, o cliente realiza consultas clínicas e/ou especializadas, exames laboratoriais e radiodiagnósticos, ou seja, o "corpo passa de mão em mão" até encontrar o seu destino, que pode ser o acompanhamento ambulatorial e/ou internação.

Além de passar "de mão em mão", o período pré-internação é moroso e prolongado, pois nem sempre há vagas para realização de exames, consulta com especialista ou leito hospitalar disponível, o que revela as deficiências e sujeição destes clientes ao sistema público de saúde. Alguns clientes se sentem tão indignados que desistem do seu tratamento, recorrendo ao hospital em situações mais graves.

O caminho a ser percorrido pelo cliente desde a chegada até a sua saída, ou seja, internação, tratamento e alta é concretamente traçado pelas lógicas:

a) da instituição, esta visa atender à doença e sua manifestação física, disponibilizando recursos materiais, humanos e aparatos tecnológicos;

b) dos profissionais de saúde que ali atuam ao definir "quem e quantos" podem percorrê-lo. Esta lógica se apóia no saber científico e separa o ser humano do seu corpo, determina padrões de normalidade/doença e de gravidade, identifica quem entra para o hospital, o espaço a ser ocupado e que prioridades devem ser atendidas;

c) do saber construído sobre este sujeito, um saber fragmentado, onde o corpo é concebido como objeto de manipulação e ganha importância na medida em que pode ser devassado pelo olhar e pelo fazer de quem "sabe" como tratá-lo, bem como daqueles que o utilizam para "treinar" esse olhar e esse fazer. Entretanto, o processo de construção deste saber não se revela como algo maquineísta, uma vez que o trabalho médico se limita a realizar isto e não outra coisa, não é sua função fazer algo diferente, ou seja, se preocupar com a dor do cliente, seus conflitos, medo de ficar internado, suas angústias.

Ao tomar o corpo anátomo-fisiológico como seu objeto, o trabalho médico não se dirige especificamente para o desvendamento das regularidades da ciência biológica, e sim, para a obtenção de seus efeitos específicos, orientados pela concepção do que é considerado saúde ou doença para o corpo.

A função desempenhada pelo saber médico na construção e controle do corpo ganha, por extensão, o estatuto de teorias das necessidades e, com isso, o poder de regulamentá-las, servindo de parâmetro para suas formas de existência social. Isto é, ao fazer equivaler o conhecimento cientificamente estruturado sobre o objeto e as necessidades humanas, o saber se transforma em prática capaz de definir o que é e o que não é legítimo, enquanto normal e patológico. ${ }^{2}$

Em seguida, o cliente passa pelo serviço de registro e documentação, no qual, mediante o fornecimento de informações pessoais, preenche um formulário e recebe o número de registro que o identificará como pertencente ao hospital e à clínica de destino.

Nesse momento, os fatos de sua doença considerados importantes passam a ser registrados, pelo médico, num documento denominado "prontuário do paciente”, a doença adquire um nome científico, uma forma e passa a ser comunicada por meio de linguagem cifrada.

Paciente admitido às 17: 00h na clínica médica veio acompanbado do maqueiro, sendo trazido em cadeira de rodas. Negro, viúvo, sem filhos, 65 anos, católico. Refere que há 11 anos apareceu lesão ulcerada em MID, o qual não cicatrizava, procurou assistência médica e foi diagnosticado LTA, sendo tratado, porém a doença veio reincidindo por todos esses anos. Relata que há 2 meses notou aparecimento de lesão na região frontal e asas de nariz, externamente, acompanbado de tosse seca e dispnéia de repouso que piorava com a deambulação. 
Apresenta astenia, anorexia e tontura com perda de $12 \mathrm{Kg}$ em 2 meses. REG, hipocorado $(+/++++)$, desidratado $(+/++++)$, presença de lesão em região frontal e asas de nariz interna e externamente com crostas endurecidas, indolores, algumas com bordas infiltradas. Boca sem lesão, dentes em péssimo estado de conservação, halitose. Abdome plano sem abaulamento ou retraçôs, presença de circulação colateral em abdome superior, ausência de visceromegalia. MMII presença de lesão cicatricial em dorso de pé " $D$ ", região anterior da perna " $D$ " e de lesão cicatricial em cotovelo " $D$ " com áreas hipocrômicas. SSVV: P $100 \mathrm{bcpm}, \mathrm{T} 36^{\circ} \mathrm{C}$, FR $32 \mathrm{irpm}$, $P A 130 \times 80 \mathrm{mmHg}$ (Registro da enfermeira no momento de admissão - prontuário do cliente).

A partir do momento que o cliente adentra o hospital, este passa a ser tratado como parte da grande "massa" de clientes hospitalizados. $\mathrm{Na}$ admissão ele perde alguns papéis que vão além da barreira geográfica, ou seja, ocorre a separação entre o mundo exterior com o mundo do hospital.

O mundo exterior é o mundo do trabalho, da produção, do ganho salarial, da realização profissional; da família e do seu entorno afetivo e simbólico dos papéis que desempenha como pai/mãe, cidadã(o), líder comunitário; é o mundo da vida que pulsa e caminha em várias direções, toma decisões, enfim, um mundo no qual o sujeito se percebe e age com relativa autonomia, liberdade de deslocamento (ir e vir quando e para onde quiser) e de expressão (sentimentos de amor, ódio, raiva, esperança).

O mundo do hospital é o mundo da doença, da produção de novos saberes, onde o saber científico se sobrepõe ao saber e experiências adquiridas ao longo da vida, da técnica que orienta os profissionais a tocar/manipular o corpo, da hierarquia, da ordem e da rotina, da identificação - pelo número de registro, enfermaria, leito, patologia. É um mundo organizado de forma tão peculiar que, à medida que o cliente penetra no seu interior, vai ganhando outra identidade, a de "paciente".

O percurso em direção ao tornar-se paciente inicia com o banho, uma simbolização ao desapego, a tudo que fica lá fora, à outra vida, o que prossegue com o vestir a roupa do hospital, com o ato de se desfazer de seus objetos pessoais, ser objeto de uma ficha médica e alvo de determinadas atribuições que outros estabelecem, não ter direito à correspondência privada, ter um lugar e hora certa para cada atividade - momento de calar e falar, de dormir e comer, até mesmo ficar sem comer, entrar e sair - ter atribuições quanto à limpeza e ordem na enfermaria. ${ }^{3}$
Atualmente a construção da identidade "paciente" no mundo do hospital passa pelo desfazer de sua privacidade, relações familiares e sociais, ou seja, deixar de ser autor de sua própria história/autonomia para se tornar objeto da ficha médica. A partir deste momento o foco de atenção e registro se volta para parte de sua história de vida (história da doença atual) e a observação de sinais/sintomas; enfim, o hospital é um mundo no qual o corpo necessita ser fixado num espaço para que possa ser cuidado e vigiado.

Podemos dizer que o processo de admissão é uma das primeiras manifestações/visibilidade do poder que se revelam "cristalizadas" no hospital; um poder capaz de envolver, enquadrar o indivíduo, conformando-o, codificando-o como um objeto que ao ser inserido na máquina assistencial obtém como produto um sujeito obediente, pronto para fazer "rodar" as operações de rotina. Uma rotina marcada pela fragmentação do tempo (horário para visita, exames, higienização, curativos, alimentação) e do corpo, em cujas partes, são executados técnicas e procedimentos ( $\mathrm{Rx}$ de tórax, curativo região $\mathrm{ab}-$ dominal, punção lombar, higiene oral).

Vale ressaltar que apesar do processo de admissão se revelar num primeiro momento como duro, rígido, cristalizado, esse poder é móvel e dinâmico, visto que o "poder só existe em ato, mesmo que, é claro, se inscreva num campo de possibilidade esparso que se apóia sobre estruturas permanentes" ${ }^{4: 242}$ Por isso, o processo de admissão é resultante da produção e troca de signos entre os profissionais que compõem o cenário da internação, construindo assim uma trama/rede de poderes que gradativamente vão se consolidando na estrutura hospitalar.

Em seguida, o cliente é encaminhado para o Serviço Social, onde recebe algumas orientações quanto: ao horário de visitas, à proibição de entrada de alimentos provenientes de sua residência e/ou proximidades do hospital, à restrição de pertences (somente os de uso pessoal), sendo imediatamente encaminhado à clínica de destino.

Desde o momento da chegada do cliente ao hospital para marcar a consulta, realizar os exames, a internação e a admissão na clínica, a instituição da terapêutica, até o momento da alta, podemos verificar que o doente vai sendo instruído, educado para ser obediente/submisso às normas institucionais $\mathrm{e}$ aos profissionais de saúde, por meio de orientações de como deve se comportar e onde deve circular. 
Uma educação que coloca o corpo em repouso, que restringe, que o afasta do seu mundo e, por conseguinte, de suas particularidades, para se fixar em conteúdos (normas e rotinas) que dão sustentação ao trabalho dos profissionais que atuam no hospital, como foi observado nos registros a seguir.

Não fumar nas dependências do hospital; não fažer barulho, nem falar em voz alta; evitar visitas entre pacientes sem autorização médica e da enfermagem; não manipular equipamentos hospitalares que estão na enfermaria (registro de oxigênio, vácuo); não tražer alimentos para os pacientes; seguir as orientações dos profissionais da enfermagem ou dos médicos; não épermitida a permanência de pessoas nos corredores do hospital; não entrar nos postos de enfermagem e nas copas (Recomendações gerais - normas do hospital).

O processo de instrução desenvolvido no hospital é semelhante ao da escola, pois na maioria dos casos, as instruções repassadas aos clientes tendem à proibição e interdição a serviço da racionalidade hospitalar.

Ao sair do serviço social o cliente é encaminho à clínica, onde a enfermeira assume a responsabilidade de distribuir os corpos no espaço da clínica e para isso tem se utilizado de alguns critérios tais como: nível de complexidade/gravidade do cliente, sexo, demanda da força de trabalho, a disposição dos materiais e equipamentos nas enfermarias como bicos de saída para ar comprimido, oxigênio, dentre outros.

As características do trabalho da enfermeira desenvolvido na clínica (ser detentor das informações relativas às condições do ambiente hospitalar, zelar pela funcionalidade, organizadora da assistência prestada e guardião das normas e rotinas institucionais) outorga à enfermeira um poder que, na maioria das vezes, se apresenta informal, sutil e aparentemente invisível, mas sem dúvida real. ${ }^{5}$

Por conseguinte, a enfermeira tem recepcionado o cliente de forma burocrática, fria e distanciada, assumindo muitas vezes uma postura estritamente técnica e sem se mostrar sensível à situação do outro, não dando espaço para o cliente expressar a sua angústia, medo do ambiente, preocupação com seu estado de saúde e familiares que deixou em casa.

Como se observa, o ritual de internação não acontece de forma aleatória, desordenada, mas dentro de um campo de múltiplas interações, onde atuam diversos personagens tais como o médico, o enfermeiro, o funcionário do registro, o assistente social. Nesse momento já é possível dar alguns contornos, "uma cara" ao hospital e aos profissionais que ali atuam, pois as diferentes atividades desen- volvidas por cada elemento nos diversos setores pelos quais o cliente vai passando revelam não só da identidade profissional, como também, as relações que se estabelecem dentro do hospital

\section{O corpo examinado}

O exame pode ser entendido como a avaliação daquilo que se vê, se escuta e se toca. Entretanto, se por um lado é utilizado para identificar, diferenciar e direcionar as ações/intervenções sobre o corpo do cliente; por outro, ele define a postura do examinador em relação a este corpo, na forma de pensar, de cuidar, de intervir.

Foi nos hospitais militares que primeiramente se organizou o ensino clínico. O exame dos casos, sua exposição detalhada relacionada a uma explicação possível é tradição muito antiga na experiência médica, entretanto no século XIX a clínica "não tem a obrigação de mostrar os casos, seus pontos dramáticos e seus acentos individuais, mas de manifestar em um percurso completo o círculo das doenças, ou seja, formar, constitucionalmente, um campo nosológico inteiramente estruturado". 6:65 Isso resultou na organização e construção de um "modelo padrão" de investigação, o exame clínico, que desde a sua concepção estabelece quem deve realizar o exame e os passos que devem ser seguidos.

O exame como um dos elementos que compõem a nova estrutura disciplinar do hospital, vai dar nova visibilidade ao corpo do cliente, bem como possibilitar sua decifração. A partir do exame é possível qualificar, para então classificar e, para isso, segue uma direção, de cima para baixo; é considerado o método mais importante para que se conheça a "verdade" sobre o cliente, visto que a observação das minúcias incide sobre sua vida, seu corpo.

Uma das características marcantes do exame é o seu "ritual". Aqueles que são submetidos ao exame serão diferenciados e para praticar essa operação é preciso descer aos detalhes, obedecer a um cerimonial/ritual cujo script deve ser seguido à risca.

O exame, por ser um procedimento altamente ritualizado, reúne a cerimônia do poder e da experiência, a demonstração da força e o estabelecimento da verdade, ou seja, num só mecanismo o exame possibilita a formação de certo tipo de saber e o exercício de certa forma de poder, capta o indivíduo doente numa objetivação limitadora e o sujeita a verdades de um campo de saber que, ao mesmo tempo, ele ajuda a construir. 
Assim, o exame resolve o problema dos hospitais, "onde era preciso reconhecer os doentes, expulsar os simuladores, acompanhar a evolução das doenças, verificar a eficácia dos tratamentos, descobrir os casos análogos e os começos das epidemias". 7:168

Normalmente, o exame segue uma ordem "céfalo-caudal" e se compõe de duas partes: anamnese (relato do doente sobre sua doença frente aos questionamentos do médico) e o exame físico que avalia o estado de saúde física ou mental do cliente.

No exame, o corpo é examinado nas mais variadas posições: deitado, sentado, em pé, parado e durante a marcha. Cada pormenor é avaliado, medido, auscultado, palpado, inspecionado, cheirado. Da mesma forma, suas condições de higiene, nutricionais, seus hábitos, suas expressões faciais, suas queixas são arroladas, a coerência de sua fala, o seu estado mental, tudo é alvo de escrutínio.

Um dos efeitos visíveis do exame se dá no momento em que o cliente se reconhece como um objeto singular, portador de anormalidades, tanto na sua estrutura corporal como em seus hábitos, os quais devem ser corrigidos, para que se conformem ao que é normal.

Por isso, é comum após a realização do exame, estabelecer condutas tais como: prescrever medicações, solicitar exames, determinar o intervalo de verificação da temperatura, pressão arterial, realização de curativos (2 ou 3 vezes ao dia), mudanças de decúbito, dentre outras, instituindo assim, não só medidas para a recuperação dos desvios/padrões de irregularidades detectadas, como também uma disciplina ao corpo.

Além disso, esse procedimento implica em distanciamento, demonstração de força e estabelecimento de verdade; "no exame estão envolvidos um campo de saber e um tipo de poder e nessa superposição de relações de poder/saber, o exame assume todo o seu brilho". 7:154

A enfermagem, apesar de ter o seu exame físico estruturado no modelo médico, tem se esforçado para fazer releituras desse ritual de uma forma própria. Florence Nightingale já no século XIX propõe um exame físico diferenciado ao voltar o seu olhar não só para as alterações fisiológicas que acometem o doente, mas ir além do que um rosto corado ou pálido possa significar, se detendo em observar as peculiaridades de cada um. "Um gosta de sofrer sozinho, de ser o menos auxiliado possível, o outro prefere ser objeto de preocupação constante" ${ }^{8: 130} \mathrm{~A}$ falta de apetite está muitas vezes relacionada com o "preparo inadequado do alimento, escolha inadequada da dieta e horários de refeição inadequados" 8:124 Enfim, um exame que buscou se apoiar também em bases humanísticas.

O ritual de exame atinge a sua máxima eficácia e legitimidade no momento da visita médica, quando o saber produzido, o diagnóstico, é validado pelos seus pares, outorgando poder ao médico para intervir sobre o corpo do cliente. A visita médica dá visibilidade e reforça o poder médico na instituição, qualifica a informação, disciplina os sujeitos e organiza o próprio corpo médico dentro das especialidades.

Durante a visita o cliente se comporta de forma passiva, obediente, assustado, sem entender o que realmente está acontecendo com sua saúde em virtude da quantidade de pessoas em volta de seu leito discutindo o seu caso, bem como pela dificuldade de entendimento da linguagem utilizada (termos técnicos).

Assim, a clínica assume uma função eminentemente pedagógica, desaparece a diferença entre sintoma e doença. A doença não é mais de natureza oculta; sua essência é a própria manifestação sensível enquanto fenômeno. Ela passa a ser concebida como um conjunto de sintomas passíveis de serem apreensíveis e decifráveis pelos números, pelo olhar, fala/linguagem, a ponto de se constituir como verdade manifesta e registrada na qualidade de evolução médica como se observa nos registros a seguir:

[...] resultado de exames: Hemocultura - 11.10.00. (+) Streptococus bovis, sensivel à penicilina; Hemograma - (17.10.00) Rcc 4.23,Ht 34,5, Hb 11.4, WBC 12.000, Neu 8.76, Lin 2.25; Bioquímica (17.10.00) Ur 34, Cr 1.20 , Na 137, K 4.9. Conduta propedêutica - Rx Tórax PA, Pe Laurell D; Análise-paciente referiu episódio de dispnéia ontem, porém hoje se encontrava eupneico, sendo observado diminnição de MV à direita com estertores crepitantes em base de HTD. Manteve-se afebril e solicitamos novo Raio- $X$ de tórax, que avaliaremos (Residente + interno).

Portanto, se de um lado o exame e a "verdade clínica" produzida por ele aproximou o conhecimento à conduta médica, auxiliando-o a traçar o programa terapêutico e a antever seu prognóstico, por outro, afastou o médico do cliente portador de doença ao relegar ou banalizar outras dimensões do humano e de seus valores, como o respeito, a compaixão, a solidariedade e principalmente o diálogo.

A enfermagem vive um momento em que enfrenta um conflito de base ao tentar desenvolver práticas diferenciadas, construir novas teorias 
sobre o corpo e maneiras de cuidar. No entanto, permanece mergulhada no "corpo do hospital", com quase nenhuma flexibilidade na forma de pensar e de agir. Daí o grande questionamento: até que ponto a enfermagem vai conseguir fazer "algo diferente", uma vez que a clínica ainda é definidora das ações de cuidado e de intervenção?

Ainda não se tem a resposta; é preciso lembrar que as diferentes forças (clínica, exame, rotina) têm o poder de constituir o outro e que a enfermagem vem se esforçando para reconstruir o corpo do cuidado de outra forma. No entanto, ela não encontra força suficiente para "romper" e "desmontar" o modelo clínico; no máximo consegue "afrouxar suas amarras” e provocar alguns abalos nessa estrutura no momento em que procura atender o cliente na sua individualidade, possibilitando a permanência de um familiar ao seu lado proporcionando-lhe maior segurança, flexibilizando algumas rotinas.

Assim como a visita médica dá visibilidade ao poder médico, a passagem de plantão dá visibilidade ao trabalho da enfermeira no que se refere ao controle e cuidado com o corpo. No entanto, este ritual apresenta algumas diferenças em relação ao ritual da visita médica como pode ser observado no registro a seguir:

[...] a passagem de plantão acontece após cada período de 6 ou 12 horas de plantão (7:00, 13:00, 19:00 e 6:00 horas). Nesse momento, a enfermeira e sua equipe de trabalho se colocam diante do leito de cada cliente para repassar as informações referentes ao estado de saúde de cada um, os exames realizados, as alterações ocorridas no plantão, os cuidados prestados (banho, jejum, curativo), a história e estado geral dos clientes admitidos, dentre outros. Este ritual acontece de maneira menos formal que a visita médica, alguns clientes se sentem à vontade que aproveitam a oportunidade para tirar dúvidas, principalmente, no que se refere ao horário de exames e jejuns, outros participam desse momento completando as informações que estão sendo repassadas ao grupo (Registro de observação).

Esses rituais revelam que o corpo do cuidado construído dentro do hospital não é o corpo da vida - corpo que se vê se reconhece que vivencia sentimentos (amor, ódio, raiva) próprios do ser humano, mas é o corpo da vida tomado pela doença. Por outro lado, quando os profissionais de saúde estão construindo esse corpo pelo saber eles também estão construindo este lugar chamado hospital, que funciona assim, obedecendo a uma lógica organizadora, legitimadora, disciplinadora e "sabedora" destes corpos.
O hospital se revela como um corpo construído, mas que ao mesmo tempo, é um "corpo que constrói corpos”. Corpo construído para abrigar e educar outros corpos a se tornarem corpos obedientes e subjetivados.

\section{O CUIDADO DE ENFERMAGEM E SUA DINÂMICA NO ESPAÇO HOSPITALAR}

A modulação/dinâmica do cuidado desenvolvido no hospital revelou que além de disciplinar os corpos, o cuidado:

- constrói domínios - divididos entre os diferentes agentes que prestam o cuidado. O corpo passa a ser apropriado em múltiplos domínios exigindo para cada pequena apropriação um conhecimento diferenciado. Por conseguinte, o corpo produzido é um corpo esfacelado;

- necessita ser administrado - para isso são estabelecidas regras implícitas e explícitas, que auxiliam a enfermeira a prever e distribuir os recursos humanos e materiais para o pleno desenvolvimento do cuidado, bem como administrar suas carências, exigindo do profissional habilidade, "jogo de cintura" ao se relacionar com sua equipe. Embora o conhecimento de Teorias Administrativas/Resoluções profissionais possa auxiliar o planejamento do cuidado, a enfermeira no cotidiano de seu trabalho, constrói outras regras e conhecimentos "práticos" visto que administra o imediato, o imprevisto. Isso contribui para que se crie nova regra, novas terminologias, novos instrumentos para administrar o cuidado;

- é rotinizado - obedece a uma ordem, é serializado, determina quando, como e quem deve realizar o cuidado. Esse cuidado produz um corpo despersonalizado, autômato, massificado, docilizado, nega ao cliente a possibilidade de existência de singularidades e diferenças entre os sujeitos, facilitando o seu controle pela norma;

- coloca em jogo os diferentes interesses profissionais, visões e poderes que circulam no hospital - na intrincada rede de interesses, lutas por espaços conquistados e por conquistar dentro do hospital, o cliente se revela simplesmente como expectador do seu cuidado e do seu corpo, o qual em alguns momentos se apresenta como um palco de lutas e resistências entre a equipe de saúde;

- se apóia no modelo biomédico de saúde, centrado na doença, nos sinais e sintomas. A enfermagem, ao sustentar suas ações no modelo 
biomédico, como tecnologia hegemônica no trabalho hospitalar, fragmentou o corpo, organizou o ambiente e instituiu mecanismos disciplinares, em particular, a vigilância. Assim, direcionou as atividades de cuidado no sentido de acompanhar os pequenos funcionamentos do corpo naquilo que se revela como "vida que pulsa", ou seja, no corpo que respira, que se alimenta, que dorme, que sente dor, que cheira.

Ao observar atentamente a realidade do cuidado desenvolvido pela enfermagem, em muitos momentos fui tomada pela dúvida: até que ponto o olhar da enfermagem se diferencia do olhar médico? Até que ponto este olhar quer ser diferente? Talvez pudéssemos responder a esse questionamento dizendo que o olhar médico tem se voltado para o funcionamento do corpo, com o objetivo de diagnosticar, classificar estabelecer estratégias de intervenção para promover a cura; e o olhar da enfermagem aos pequenos funcionamentos deste corpo, a fim de mantê-lo sob vigilância; conhecer o seu funcionamento para poder atuar no sentido de reconduzi-lo à ordem.

Pensar no cuidado de enfermagem como o lugar de cuidado às pessoas é pensar em complexidade, aceitar a ambigüidade nas relações entre o sujeito cuidador (a) e o sujeito que é cuidado aceitando a ordem/desordem a auto/hetero organização. Isto exige o reconhecimento de fenômenos, tais como liberdade e criatividade, qualidades inexistentes no modelo biomédico.

\section{CONSIDERAÇÕES FINAIS}

Ao voltar o olhar para o ritual de internação e exame físico e dinâmica do cuidado verificamos que no contexto hospitalar, convive-se com corpos portadores de enfermidades e afecções que foram e/ou se encontram submetidos às terapias, corpos que expressam em si os dilemas dos controles sociais e da regulação institucional, ${ }^{9}$ corpos obedientes aparentemente frágeis, que encontra forças para resistir às "regras" de boa conduta cristalizada na estrutura hospitalar, constituindo-se em "corpo rebelde".

Portanto, a enfermagem tem um compromisso consigo mesma e com a humanidade, necessita encontrar forças para “desconstruir" esse modelo perverso (biomédico) e "reconstruir" sua prática valorizando a fala, as respostas e experiências humanas nos diferentes ciclos da vida: saúde, doença, viver, morrer, nascer, crescer, sofrer, aprender, transformar.

Com isso, a enfermagem e as demais ciências da saúde se vêem impelidas a ampliar seu universo de leitura e codificação, introduzindo elementos antes considerados extra-sistêmicos ao seu ritual de internação e de exame tais como: o corpo cultural e histórico, o corpo semiótico feito de sinais e símbolos, de histórias e lendas, de imaginação e fantasia, de sonhos e brincadeiras, de jogos e papéis sociais, de personagens imaginários, de mitos e de crenças, do vivido e do desejado, dos saberes e dos sabores, dos seus temores e ansiedades, enfim um corpo feito também de paixões. ${ }^{10}$

\section{REFERÊNCIAS}

1 Foucault M. Microfísica do poder. 15a ed. Rio de Janeiro (RJ): Graal; 2000.

2 Mendes-Gonçalves RB. Tecnologia e organização social das práticas de saúde: características tecnológicas do processo de trabalho na rede estadual de centros de saúde de São Paulo. São Paulo (SP): HUCITEC/ ABRASCO; 1994.

3 Kruse MHL. Os poderes dos corpos frios: das coisas que se ensinam às enfermeiras [tese]. Porto Alegre (RS): UFRGS/Departamento de Educação; 2003.

4 Dreyfus HL, Rabinow P. Michel Foucault, uma trajetória filosófica: para além do estruturalismo e da hermenêutica. Rio de Janeiro (RJ): Forense Universitária; 1995.

5 Borenstein MS. Poder da enfermagem no espaço hospitalar. Texto Contexto Enferm. 2000 Ago-Set; 9 (3): 42-53.

6 Foucault M. O nascimento da clínica. 5a ed. Rio de Janeiro (RJ): Forense Universitária; 2001.

7 Foucault M. Vigiar e punir: nascimento da prisão. 13a ed. Petrópolis (RJ): Vozes; 1996.

8 Nigthingale, F. Notas sobre enfermagem. São Paulo (SP): Cortez/ ABEn-CEPEn; 1989.

9 Polak Y. A concepção de corpo no mundo da saúde. Cogitare Enferm. 1996. Jan-Jun; 1 (1): 4-9.

10 Urasaki MBM. A transformação: do cuidar mecânico ao cuidar sensível. Rev. Paulista Enferm. 2003 JanAbr; 22 (1): 72-81. 